\title{
A clinical and radiographic evaluation of the management of periodontal osseous defects with alloplast and platelet rich plasma
}

\author{
Shreya Shetty* and Aditi Bose \\ *Correspondence: drshreyak@gmail.com \\ Department of Periodontics, Bangalore Institute of Dental Sciences and Postgraduate, Research, Hosur road, Bangalore, India.
}

\begin{abstract}
Background and objectives: Tissue engineering is fast gaining popularity in the field of periodontics, as periodontal disease is a complex condition, involving destruction of vital tooth supporting structures. Therefore, regeneration of these tissues lost due to disease in order to restore normal oral health and integrity is imperative. Research in this field has had far reaching consequences and conflicting reports. Although bone grafts and other regenerative options have been evolving over the last few decades, the most recent innovation in this field has been the advent of platelet rich plasma (PRP) and its derivative platelet rich fibrin (PRF). The purpose of this study was to evaluate clinically and radiographically, periodontal regeneration/alveolar bone fill with the use of synthetic alloplast (Biograft-HT) alone and with a combination of platelet rich plasma (PRP) in the treatment of human periodontal intrabony defects.
\end{abstract}

Methods: In this randomized controlled study, 15 patients (30 intrabony defects) in the age range of 25-55 years, showing bilaterally similar but not identical intrabony defects were selected. The defects were assigned randomly to Test site (PRP with Biograft-HT) and Control site (Biograft-HT alone). The clinical parameters recorded were gingival index, plaque index, probing pocket depth and relative attachment level at 0,3,6 and 9 months. The radiographic parameters recorded were radiographic defect depth and percentage bone fill at baseline, and at 9 months post-operatively, using standardized intra-oral periapical radiographs taken with long cone paralleling technique, which were then assessed using computer assisted image analysis software.

Results: Statistical analysis using ' $t$ ' tests and Mann-Whitney tests revealed that there was a significant reduction in gingival index, plaque index, probing pocket depth and gain in clinical attachment level at the various time intervals within both the groups. Radiographic evaluation revealed statistically significant defect fill $(\mathrm{p}<0.001)$ at the end of 9 months within both test and control groups. However, the differences in the mean scores between the 2 groups were not statistically significant both clinically and radiographically.

Interpretation and conclusion: Both groups showed potential in enhancing periodontal regeneration; however the results with PRP with Biograft-HT were comparatively better, although not statistically significant when compared to BiograftHT alone.

Keywords: Periodontal regeneration, platelet rich plasma, alloplasts (synthetic bone grafts), platelet rich fibrin

\section{Introduction}

Periodontitis involves an inflammatory process, of multifactorial origin, affecting the periodontal tissues viz alveolar bone, periodontal ligament, cementum of the tooth and gingiva, and provoking the destruction of the supporting tissues to the teeth. The ultimate goal of periodontal therapy is to regenerate the lost periodontal tissues caused by periodontitis [1]. The advent of regenerative approaches in contemporary periodontics has increased patient's treatment options and enhanced the long- term prognosis of many teeth that have advanced periodontal destruction. Regenerative procedures have been evaluated in several studies using grafting materials, tooth root surface conditioning, guided tissue regeneration and application of growth factors [1-4].

Porous hydroxyapatite bone augmentation material has been used to fill periodontal intrabony defects, which has resulted in clinically acceptable responses [5]. Hydroxyapatite (HA) has good biocompatibility when in contact with bone as its chemical composition is similar to that of bone. Tricalcium phosphate, a calcium salt of phosphoric acid has an alpha and a beta crystal form. It can be used as a tissue replacement for repairing bony defects when autogenous bone graft is not feasible or possible [6-8]. HA and B-TCP have been widely used as bone substitutes. They are biocompatible, non-toxic, resorbable, and non-inflammatory; cause no immunological, foreign-body, or irritating response; and have excellent osteoconductive ability.

The next line of regenerative materials which have gained popularity are Growth factors, a class of polypeptide hormones known to promote proliferation and migration of periodontal ligament cells, synthesis of extracellular matrix as well as differentiation of cementoblasts and osteoblasts. They

(c) 2013 Shetty et al; licensee Herbert Publications Ltd. This is an Open Access article distributed under the terms of Creative Commons Attribution License (http://creativecommons.org/licenses/by/3.0). This permits unrestricted use, distribution, and reproduction in any medium, provided the original work is properly cited. 
have been suggested to represent a potential aid in an attempt to regenerate the periodontium [9]. Growth factors that seem to play an important role in periodontal and bone wound healing are platelet derived growth factor (PDGF), insulin-like growth factor (IGF) combined with PDGF and transforming growth factor $\beta$ (TGF- $\beta$ ) [9]. PDGF has been shown to exert a favorable effect on periodontal regeneration as measured by increase in clinical attachment levels and osseous defect fill in humans [10]. Topical application of TGF- $\beta$ has shown to stimulate proliferation of gingival fibroblastic cells, formation of blood vessels and remodeling of extracellular matrix, which results in increased proliferation of granulation tissue within healing periodontal tissues. TGF- $\beta$ when coated onto $\beta$ tricalcium phosphate pellets have shown to substantially stimulate cell proliferation and differentiation of osteoblast lineage cells and induce bone formation in rat calvarial osseous defects [11].

Growth factors are known to be abundant in a granules of platelets. A convenient and economical approach to obtain autologous PDGF and TGF- $\beta$ is the use of platelet rich plasma (PRP) [12]. PRP is a component of blood in which the platelets are concentrated in a limited volume of plasma. Autologous platelet gel was first developed as a byproduct of multicomponent pheresis. The platelet count in PRP can exceed 2 million platelets per micro liter. A natural blood clot contains $95 \%$ red blood cells, 5\% platelets, less than $1 \%$ white blood cells, and numerous amounts of fibrin strands. A PRP blood clot contains $4 \%$ red blood cells, $95 \%$ platelets, and $1 \%$ white blood cells. It can be considered that PRP "jump starts" the cascade of regenerative events leading to the formation of a mature graft site [13]. The PRP obtained offers up to a 2.16-times increase in the maturation rate and substantially greater density of a bone graft procedure [14].

Many applications of PRP include, sinus lift procedures, onlay grafts, particulate grafts, alveolar cleft palate repair, oral/nasal fistula repair, post-operative hemostasis of bone graft donor sites, continuity defects of the mandible and hemophiliacs undergoing surgery. In periodontal surgery it has been used in gingival grafting, crown lengthening, ridge augmentation, implant procedures and periodontal regeneration.

The use of porous HA+ $\beta$ TCP and PRP in a combination for periodontal regenerative therapy offers a potentially useful modality to the clinician in treating periodontal intrabony defects. However, only a few clinical trials have tested the efficacy of a combination of PRP and bone grafts in the treatment of intrabony defects [12,15-17]. It is yet unknown whether a combination of HA+ $\beta$ TCP and PRP may enhance the outcome of therapy. Therefore, the purpose of this prospective, randomized controlled study was to compare the clinical and radiographic outcomes obtained by a combination of $\mathrm{HA}+\beta$ TCP and PRP to $\mathrm{HA}+\beta$ TCP alone in treatment of periodontal intrabony defects.

\section{Materials and methods}

The research protocol and study design was initially submitted to the Institutional Ethical Committee and Review Board, Bangalore Institute of Dental Sciences and Hospital and Research Centre, Bangalore. After initial approval, all patients received verbal information regarding participation, and written informed consent was obtained for participation in the study.

Following the final approval of the Ethical committee, a total of 28 systemically healthy patients with chronic periodontitis (13 males and 15 females; age range of 25 55 years) were screened in the outpatient section of the Department of Periodontics at the institute in the period between September 2011 to November 2012.

Patients with any systemic condition or disease, compromised immune system, pregnant or lactating women, physically or mentally challenged patients, patients taking drugs known to cause gingival enlargement, those allergic or sensitive to any of the medications to be used in the study, those not maintaining optimum oral hygiene in the course of the follow up visits were excluded from the study.

After the initial assessment, scaling and root planning of all the teeth was performed as part of phase 1 therapy which also included oral hygiene instructions and maintenance recalls. Plaque control programme varied in duration depending upon the response of the patients.

Six to 8 weeks after the phase 1 therapy, a periodontal evaluation was performed to confirm the desired sites for the study.

Patients with still existing one or more bilateral intrabony pockets (in same arch) or unilateral intrabony pockets (in different arches) with probing depth of $\geq 5 \mathrm{~mm}$ with osseous defects were enrolled for the study. Only 15 patients fulfilled the above inclusion criteria, thus a total of 30 sites (using split-mouth design) were then segregated randomly into test group (15 sites) and control group (15 sites). The nature and purpose of the study was explained to the patients and written consent was obtained. The patients in the test group were treated with platelet-rich plasma [PRP] and synthetic bone replacement alloplast (biograft-HT). The control group patients were treated with biograft-HT alone. The results were evaluated clinically and radiographically (with intra-oral periapical X-rays) at 0,6 and 9 months.

\section{Clinical and radiographic measurements}

Clinical parameters recorded before surgical procedures included the site-specific Plaque index(PI), Gingival index(Gl), Pocket depth(PD) from the gingival margin, relative attachment level (RAL) and depth of the osseous defects from the apical level of customized acrylic stents with grooves to ensure a reproducible placement of the periodontal probe. All intrabony defects were evaluated at baseline and 9 months postoperatively.

Intraoral periapical radiographs were taken by long cone/ 


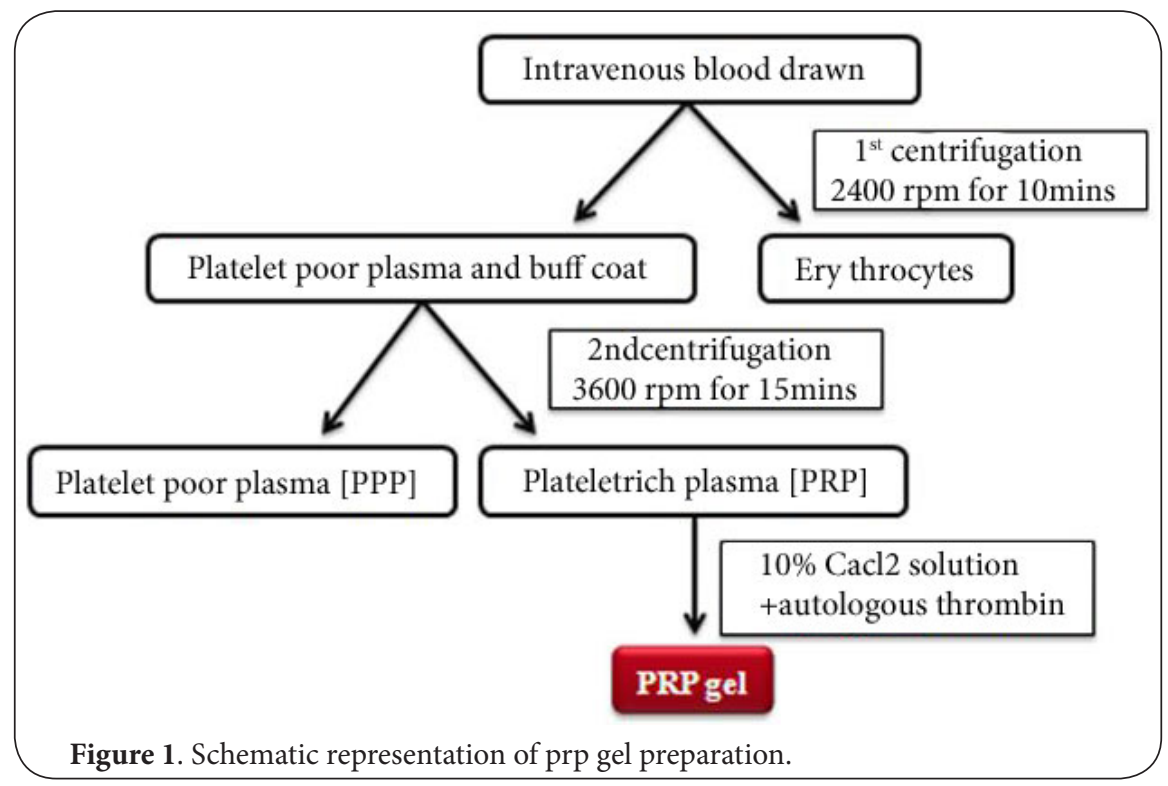

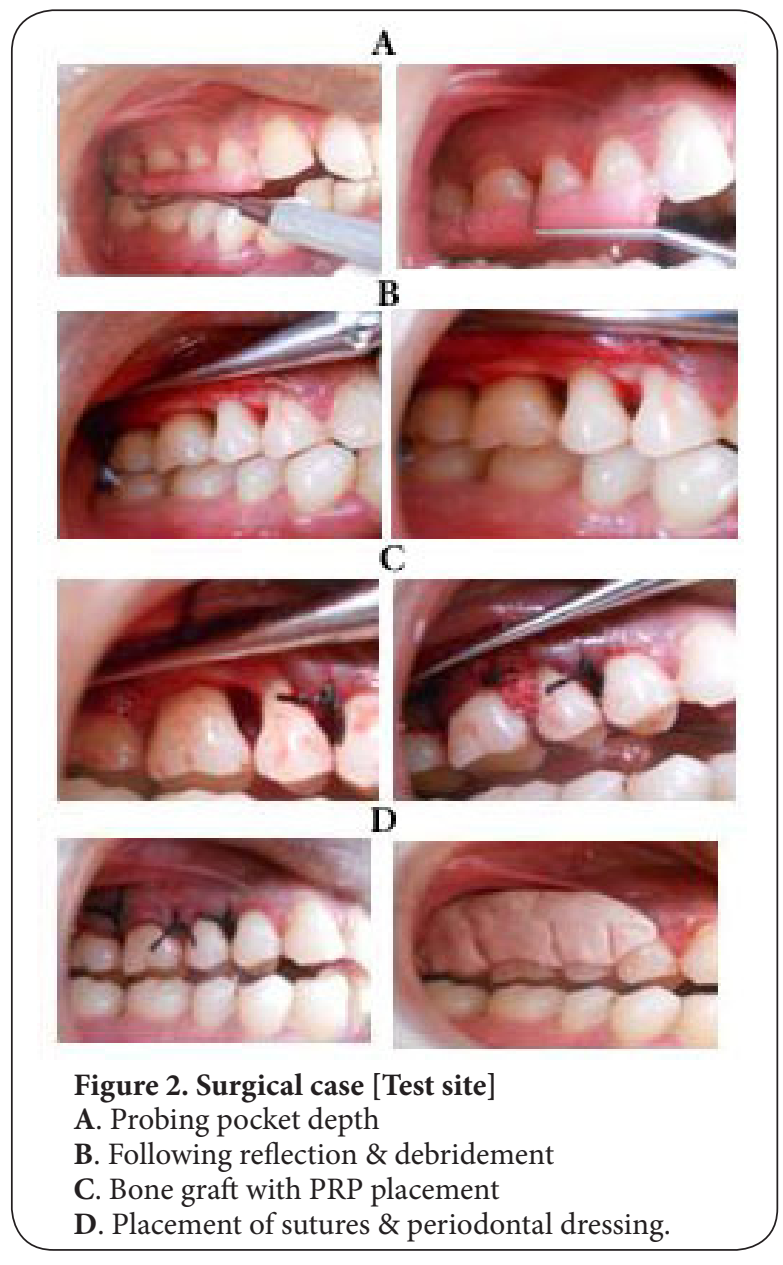

extension cone paralleling technique using a KentzlerKaschner dental-starter kit (Germany) positioning device and a size $2 \mathrm{E}$ speed Kodak IOPA $\mathrm{x}$-ray film in a $\mathrm{x}$-ray unit
(70kVp, 15mA, 0.6mAs). This was carried out at baseline and at 6 and 9 months post-operatively. These radiographs were scanned and Computer Assisted Image Analysis of the radiographs was done with the help of image analysis software.

\section{Preparation of platelet-rich plasma (PRP)}

(Figure 1) Platelet-rich plasma (PRP) was prepared according to the procedure described by Robert Marx [12]. One hour prior to the periodontal surgery $10 \mathrm{ml}$ of whole blood was drawn from each subject by venipuncture of antecubital vein. Blood was collected in a vacutainer (VACUTTE-Greiner bio-one) coated with an anticoagulant (3.2\% sodium citrate). The tubes were inverted several times to ensure the mixing of blood and anticoagulant. The whole blood was initially centrifuged in a REMI digital centrifugal device at 5400rpm for 10 minutes to separate the PRP and plateletpoor plasma (PPP) from the red blood cell fraction. The PPP was discarded, leaving just about $1 \mathrm{ml}$ of PPP present above the buffy coat. The $1 \mathrm{ml}$ of PPP, the whole of buffy coat and $1 \mathrm{ml}$ of red blood cell fraction rich in newly synthesized platelets was pipetted out and transferred to another test tube without an anticoagulant. The test tubes were centrifuged at $2400 \mathrm{rpm}$ for 12 minutes, to separate the PRP and PPP. The PRP was then drawn into a syringe and expressed into a sterile container.

\section{Treatment procedure}

(Figures 2 and 3) All periodontal surgical procedures were performed on an outpatient basis under aseptic conditions. Surgical area was anesthetized using local anesthetic ( $2 \%$ lignocaine with adrenaline 1:80,000). Intracrevicular incisions were made and full thickness mucoperiosteal flaps were elevated, to retain as much soft tissue as possible in order to obtain primary closure. The periodontal surgical procedure 

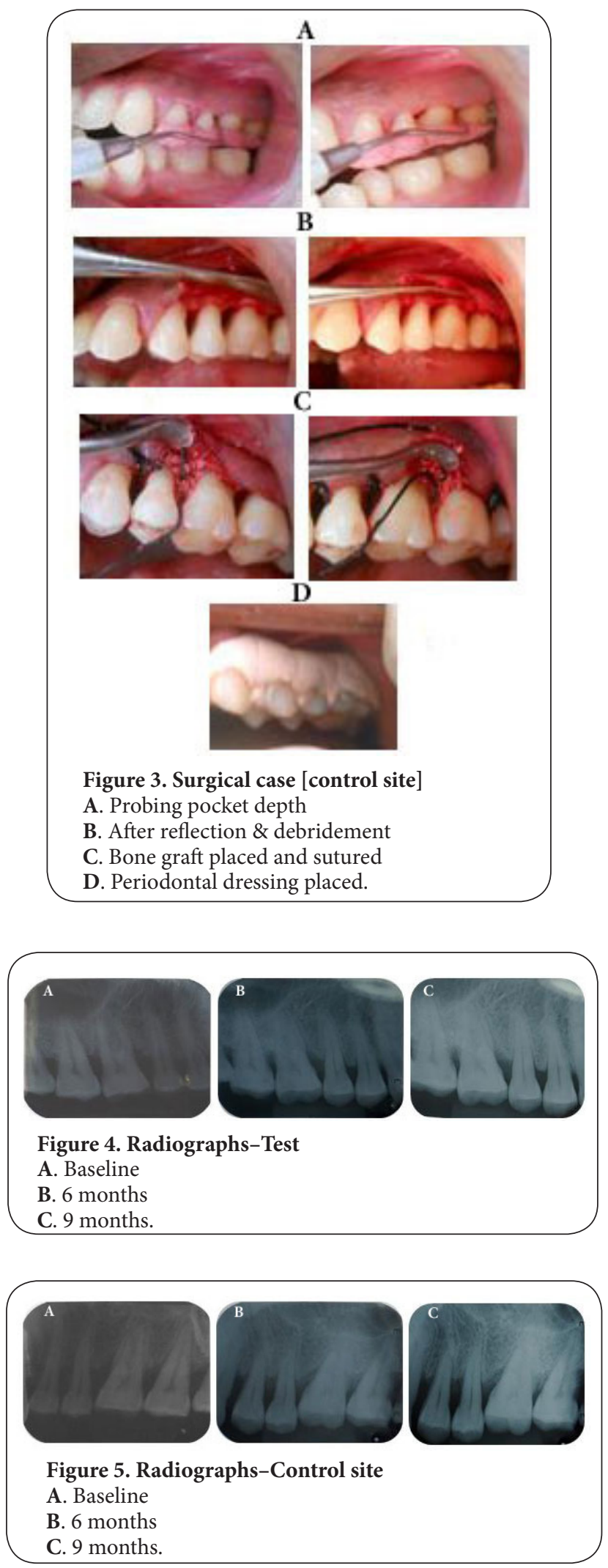

fully exposed the intrabony defects. Meticulous defect debridement and root planing were carried out to remove subgingival plaque, calculus, diseased granulation tissue and pocket epithelium. The surgical sites were irrigated with sterile saline and care was taken to keep the area free of saliva. Measurement of the osseous defect was made utilizing the stent and Williams graduated probe.

Immediately before application the PRP was activated by clot initiator (100 IU of lyophilized human thrombin with $1 \mathrm{ml}$ of $10 \% \mathrm{CaCl} 2$ solution). Within a few seconds, the PRP preparation assumed a sticky gel consistency. Depending on the extent of the intrabony osseous defect the coagulated PRP + biograft-HT mixture or biograftHT alone was placed upto the vertical height of the corresponding adjacent bone level. Surgical flaps were repositioned to the presurgical level and sutured with 3-0 silk suture utilizing an interdental, direct suturing technique achieving primary closure. Care was taken not to displace the graft material during suturing. A periodontal dressing (Coe-pak) was placed on the surgical area.

\section{Post operative care}

Postoperative care included systemic administration of amoxicillin $500 \mathrm{mg}$ thrice daily for 5 days and a non-steroidal anti-inflammatory agent thrice daily for 5 days and $0.12 \%$ chlorhexidine gluconate rinse twice daily for a period of 2 weeks. One week following surgery, the periodontal dressing and sutures were removed and the area was irrigated thoroughly with saline.

Recall appointments were made after 1 month, 3months, 6 months and 9 months post-surgery and at each visit, the clinical parameters were recorded, oral hygiene instructions were reinforced and scaling was done whenever necessary. Radiographs were taken at 6 and 9 months respectively. (Figures 4 and 5).

\section{Statistical analysis}

All the clinical parameters were recorded at baseline, 3, 6 and 9 months. The radiographic measurements were recorded at baseline, 6 and 9 months post-operatively. All the data were subjected to statistical analysis. Frequency tables and measures of central tendency were obtained by using the statistical package SPSS for comparison of mean values of test and control groups across various parameters at each time period. Clinical and radiographic parameters were subjected to student ' $\mathrm{t}$ ' test and the ' $\mathrm{t}$ ' and ' $p$ ' values were obtained with appropriate levels of significance.

Descriptive analysis that included mean, standard deviation percentages were found for each parameter in two groups and were used for analysis. Within each group, Wilcoxon Signed Ranks Test was performed to compare post treatment changes from baseline. For comparison between the inter-group variations unpaired ' $t$ ' tests was performed. Wherever the data was presumed to be nonnormal, "Mann-Whitney" test was used. A ' $p$ ' value of 0.05 or less was considered statistically significant. 


\section{Results}

\section{Gingival index}

Test site-The mean gingival index score at baseline was $1.95 \pm 0.27$ which was reduced to $1.47 \pm 0.25$ at 3 months, and further reduced to $0.97 \pm 0.27$ and $0.53 \pm 0.19$ at 6 and 9 months respectively. This difference was found to be highly statistically significant $(p<0.001)$.

Control site-The mean gingival index score at baseline was $1.95 \pm 0.22$ which was reduced to $1.48 \pm 0.26$ at 3 months, and further reduced to $0.95 \pm 0.34$ and $0.58 \pm 0.24$ at 6 and 9 months respectively. This difference was found to be highly statistically significant $(p<0.001)$.

However, comparison between the two groups revealed no statistically significant difference at 3, 6 and 9months $(p>0.05)$.

\section{Plaque index}

Test site-The mean plaque index score at baseline was $1.62 \pm 0.39$ which was reduced to $1.17 \pm 0.37$ at 3 months, and further reduced to $0.80 \pm 0.39$ and $0.42 \pm 0.28$ at 6 and 9 months respectively. This difference was found to be highly statistically significant $(p<0.001)$.

Control site-The mean plaque index score at baseline was $1.52 \pm 0.31$ which was reduced to $1.10 \pm 0.30$ at 3 months, and further reduced to $0.73 \pm 0.22$ and $0.43 \pm 0.20$ at 6 and 9 months respectively. This difference was found to be highly statistically significant $(p<0.001)$.

However, comparison between the two groups revealed no statistically significant difference at 3,6 and 9months ( $p>0.05)$.

\section{Probing pocket depth}

Test sites-The mean probing depth at baseline was $6.87 \pm 0.92 \mathrm{~mm}$ which was reduced to $5.47 \pm 0.83 \mathrm{~mm}$ at three months, and further reduced to $4.60 \pm 0.91$ and $3.87 \pm 0.74 \mathrm{~mm}$ at 6 and 9 months respectively. This difference was found to be highly statistically significant $(p<0.001)$.

Control sites-The mean probing depth at baseline was $7.13 \pm 1.55 \mathrm{~mm}$, which was reduced to $5.87 \pm 1.30 \mathrm{~mm}$ at three months, and further reduced to $4.93 \pm 1.03 \mathrm{~mm}$ and $2.90 \pm 0.54 \mathrm{~mm}$ at 6 and 9 months respectively. This difference was found to be highly statistically significant $(p<0.001)$.

Comparison between the two groups revealed no statistically significant change in probing pocket depth at 3,6 and 9 months respectively ( $p>0.05$ ).

\section{Relative attachment level}

Test sites-The mean relative attachment level at baseline was $11.40 \pm 2.10 \mathrm{~mm}$, which was reduced to $10.27 \pm 1.94 \mathrm{~mm}$ at three months. At six months, it was further reduced to $9.47 \pm 2.13 \mathrm{~mm}$ and at nine months, to $8.73 \pm 1.98 \mathrm{~mm}$. This difference at 3, 6 and 9 months was found to be highly statistically significant $(p<0.001)$.

Control sites-The mean relative attachment level at baseline was $11.73 \pm 3.13 \mathrm{~mm}$, which was reduced to $10.53 \pm 2.92 \mathrm{~mm}$ at three months. At six months, it was further reduced to $9.73 \pm 2.55 \mathrm{~mm}$ and at nine months, reduced to $9.40 \pm 2.72 \mathrm{~mm}$. This difference at 3,6 and 9 months was found to be highly statistically significant $(p<0.001)$.

Comparison between the two groups revealed no statistically significant difference in the change in relative attachment level at 3, 6 and 9 months respectively $(p>0.05)$.

\section{Radiographic evaluation}

\section{Radiographic defect depth}

Test sites-The mean radiographic defect depth at baseline was $5.40 \pm 2.03 \mathrm{~mm}$. At six months, it was reduced to $3.67 \pm 1.84 \mathrm{~mm}$ and at nine months, it was further reduced to $2.47 \pm 2.07 \mathrm{~mm}$. This difference at 6 and 9 months was found to be highly statistically significant $(p<0.001)$.

Control sites-The mean radiographic defect depth at baseline was $6.07 \pm 2.43 \mathrm{~mm}$. At six months, it was reduced to $4.20 \pm 1.66 \mathrm{~mm}$ and at nine months, it was further reduced to $3.13 \pm 1.51 \mathrm{~mm}$. This difference at 6 and 9 months was found to be highly statistically significant $(p<0.001)$.

Comparison between the two groups revealed no statistically significant difference in the reduction of radiographic defect depth at 3,6 and 9 months respectively $(p>0.05)$.

\section{Radiographic defect fill}

Test sites-The mean radiographic defect fill at six months was $1.73 \pm 0.70 \mathrm{~mm}$ which increased to $2.87 \pm 0.99 \mathrm{~mm}$ at 9 months. This difference at 6 and 9 months was found to be highly statistically significant $(p<0.001)$.

Control sites-The mean radiographic defect fill at six months was $1.87 \pm 0.99 \mathrm{~mm}$ which increased to $2.93 \pm 1.39 \mathrm{~mm}$ at 9 months. This difference at 6 and 9 months was found to be highly statistically significant $(p<0.001)$.

Comparison between the two groups revealed no statistically significant difference in the radiographic defect fill when measured at 6 and 9 months respectively $(p>0.05)$.

\section{Percentage radiographic defect fill}

Test sites-The percentage of radiographic defect fill at 6 months was $33.91 \pm 12.54 \%$ which increased to $60.04 \pm 24.84 \%$ at 9 months.

Control sites-The percentage of radiographic defect fill at 6 months was $30.37 \pm 8.67 \%$ which increased to $48.56 \pm 15.46 \%$ at 9 months.

Thus, although the test sites showed higher percentage of radiographic defect fill, no statistically significant difference in the percentage defect fill was found between the two groups when measured at 6 and 9 months respectively $(p>0.05)$.

\section{Discussion}

The primary aim of periodontal therapy is to eliminate the inflammatory processes in order to arrest the progression 
of the disease and keep the dentition in a state of health and function. The purpose is to arrest the destruction of soft tissue and bone caused by periodontal disease, and regenerate the lost tissue, if possible [18]. A deep intraosseous defect presents a major challenge in achieving the goal of regeneration as it increases the risk for disease progression and recurrence after traditional systemic therapy [19]. Therefore for regeneration of periodontal intraosseous defects, combination of different materials like root conditioning agents, guided tissue regeneration procedures, bone replacement grafts and growth and attachment factors have been used with varying degrees of success. PRP alone and in combination with hydroxyapatite [20], bovine porous bone mineral and barrier membranes [21] have been extensively researched and tested in periodontal defects. However, at present, there is no available literature about the combination of biograft and PRP in periodontal regeneration. The aim of the present study was therefore to evaluate and compare clinically and radiographically the efficacy of this novel bone graft material [Biograft- $\mathrm{HT}^{\oplus}$ ] in combination with PRP and Biograft-HT ${ }^{\oplus}$ alone (i.e., without PRP) in the treatment of periodontal intrabony defects.

The results of the study showed that there was significant reduction in the mean gingival index scores within the test and control groups from baseline to 3, 6 and 9 months respectively. However, the reduction of scores was not significant when the two groups were compared at the same intervals during the study. These findings are in accordance with the results of the studies by Okuda $\mathrm{K}$ et al., (2005) [22], Dori F et al., (2008) [23] and Kovacs V et al., (2009) [24] which have shown statistically significant changes in gingival index within the groups from baseline but no statistically significant differences were observed between the two groups. The reduction in mean plaque index scores within the test and control groups from baseline to 3, 6 and 9 months respectively was statistically significant. However, the reduction of scores was not significant between the two groups for the same intervals of the study. These findings are consistent with previous studies by Pradeep AR et al., (2009) [25], Yilmaz S et al., (2009) [26], Dori F et al., (2009) [24] and by Kaushick BT et al., (2011) [27] which have shown statistically significant changes in plaque index within the groups from baseline but no statistically significant differences were observed between the two groups. The improved gingival and plaque index scores in both the groups showed the increased level of oral health awareness among patients and a good maintenance of oral hygiene by them throughout the study period. Pocket depth resolution is not only a desirable outcome of periodontal regeneration, but may also be the most important parameter in patient care for the clinician, since it directly impacts his or her ability to instrument a treated area during the maintenance appointments. Pocket probing is not only a crucial and mandatory procedure in diagnosing periodontitis but also in evaluating periodontal therapy. There was a marked reduction in probing pocket depth within both test and control sites from baseline to 6 and 9 months which is in accordance with the studies done by Lekovic V et al., (2003) [12] and Hanna R et al., (2004) [28]. The results of the control sites compare favorably with earlier studies of biograft-HT [29]. Till date, there are no studies on PRP combined with Biograft-HT. However, the results of our study compare favorably with other studies with PRP combined with other alloplasts [23] and bovine porous bone mineral $[30,31]$.

Comparison between the two groups revealed no statistically significant reduction of probing pocket depth when measured at different points of time during the study. Similar results on comparison between two groups were obtained in previous studies [23,24,31-34], but contradictory results were found by Saini N et al., (2011), where there was significant reduction in PPD in test group compared to control group [35].

Currently, the "gold standard" for recording changes in periodontal status is longitudinal measurement of clinical attachment levels from the CEJ or a relative attachment level from a fixed reference point [36]. In the present study, we used relative attachment level (RAL), which was distance from a fixed reference point (base of the customized acrylic stent) to the base of the pocket due to inconsistency in accurately locating CEJ at the selected sites. The changes in mean relative attachment level within both the test group and control at 3,6 and 9 months was found to be highly statistically significant. This suggests that there was a statistically significant attachment gain from baseline to 9 months within both test and control sites. The results of the test sites compare favorably with earlier studies of Hanna R et al., (2004) [28] and Okuda K et al., (2005) [22] whereas the results at control sites where in accordance to the studies of Drizhal et al., (2010) [37] and Sukumar et al., (2011) [38]. Comparison between the two groups revealed no statistically significant difference in the reduction of clinical attachment level when measured at different points of time during the study, in contrast to the study of Okuda et al., (2005) [22] and Saini et al., (2011) [35] where a statistically significant gain in clinical attachment was reported with PRP in combination with other alloplastic materials, when compared to bone grafts alone [12]. The gain in the clinical attachment level has been thought to represent resolution of tissue inflammation, reformation of collagen fibers, new attachment to the root surface and the bone fill [39]. Thus effectively, both the treatment modalities resulted in a significant reduction in pocket depth and clinical attachment gain. The primary reason for reduction in depth after treatment can be attributed to the reduction in gingival inflammation and shrinkage of pocket wall. It can also occur due to combination of gain in clinical attachment as well as post treatment gingival recession [12]. Alternatively, it has also been suggested that 
placement of a graft material into a defect may modify the gingival tissue consistency, therefore impede penetration of the probe without necessarily having induced any gain in clinical attachment.

New bone formation is frequently used as a primary outcome variable in controlled clinical trials of regenerative therapy. Radiographic monitoring of alveolar bone changes following regenerative procedures is a non-invasive painless alternative to direct bone measurements which is obviously the best way to access bone formation. The radiographic variables assessed were the changes in the radiographic defect depth and the extent of defect fill and defect resolution. The minimum time required for bone changes to be evident on a radiograph is 6 months; hence radiographs were taken at 6 and 9 months respectively [28] There was a significant reduction in radiographic defect depth within both the test and control groups at 6 and 9 months thereby indicating a significantly increased defect fill and increased percentage defect fill within both the groups. These radiographic changes are in accordance with previous studies showing similar results $[\mathbf{2 2}, \mathbf{2 6}, \mathbf{2 9}, \mathbf{4 0}, \mathbf{4 1}]$. However, comparison between the two groups revealed no statistically significant difference in the reduction of radiographic defect depth or the defect fill when measured at 6 and 9 months respectively. The results of this inter group comparison were found to be similar to the results of previously conducted studies by Camargo PM et al., (2009) [31], Dori F et al., (2009) [24], Yilmaz S et al., (2011) [34] and Saini A et al., (2011) [42] but contradictory to the results of studies done by Ouyang XY et al., (2006) [40] and Saini N et al., (2011) [35], where they found significant improvement in the test sites as compared to control sites in defect depth reduction and bone fill. Significant improvement in clinical and radiological parameters both at test and control sites may also be attributed to the physical characteristic of the regenerative materials used. The type of attachment formed after periodontal regeneration can be determined accurately only by histological analysis of tissue blocks obtained from the healed area [43]. Although this method can offer clear evidence of a new attachment apparatus, it has certain limitations, the most relevant being the ethical angle and secondly, the need to remove a tooth with its periodontium after successful treatment limits this method to volunteers who need the extraction for prosthetic or other reasons.

Biograft bone regenerative materials are both biocompatible and bioactive and hydroxyapatite phase is the major constituent. These materials of porous crystalline structure provide osteoconductivity and resorbability. Hydroxyapatite has a stoichiometry similar to natural bone structure and provides an osteoconductive scaffold in the bone regenerative process [29]. Combination of PRP and biograft-HT demonstrated slightly more favorable results compared to biograft-HT alone. The precise role played by
PRP in the defect fill is difficult to determine but may be explained on the basis of tissue engineering mechanics. Tissue engineering combines three key elements for regeneration i) scaffolds or matrix ii) signaling molecules iii) cells [44]. By combining these elements under appropriate biological and environmental conditions tissue regeneration will become more predictable [44]. Applying this concept to the present study, biograft-HT could be considered a scaffold for delivery of growth factors present in PRP. The PDGF and TGF's in PRP may have worked in promoting the growth and differentiation of periodontal and alveolar bone cells rapidly in the test sites. An in vitro study by Strayhorn et al., suggested PDGF acts mostly on osteoblastic cell proliferation exerting most of its effect during early phases of wound healing, whereas TGF- $\beta$ plays a role in osteoblast and cementoblast differentiation [45]. PRP is an autologous preparation, consisting of high concentration of platelets and is therefore completely safe for the patient. Clotting was initiated with autologous human thrombin to reduce the risk of formation of cytotoxic antibody. The only drawback was the need to have a clinician proficient in drawing blood and extra time to prepare coagulated PRP for actual use. However the results obtained from PRP studies are quite contradictory. Histomorphometric analysis revealed a higher percentage of bone contact in cases where PRP was used in conjunction with bone graft [33]. Some authors showed that the filling with a PRP gel alone achieved a similar bone regeneration than the use of a membrane for guided tissue regeneration $[46,47]$ or even than the filling with a bone substitute [48]. However, other authors demonstrated that PRP alone was not able to support a significant bone regeneration [25] and that PRP should be associated to other materials in order to give good results for the healing of periodontal lesions [49]. The comparison of the data is difficult since the kind of PRPs used in these studies is once again difficult to determine, but these contradictory studies suggest that the size and form of the defect significantly conditioned the true potential of the platelet concentrate. PRP gels are indeed fragile and soft filling material, and are thus highly sensitive to mechanical constraints. When the intrabony defects present several walls and are easily protected, a platelet gel acts as a stabilized blood clot and therefore becomes the perfect filling material for a natural tissue regeneration. This kind of treatment is obviously more natural and therefore better than filling with a bone substitute that will require many years to resorb and remodel, even if the sole objective of clinical tooth stability is the same with both approaches. But when the local conditions are not optimum, PRP gels alone are not strong enough to promote a clinical filling equivalent to the dense bone filling reached with a bone substitute [50]. Most of the randomized controlled clinical trials(RCTs) demonstrated that the addition of PRP to certain regenerative materials, 
namely bioactive glass [51], b-TCP [52], BM and e-PTFE membranes [53], b-TCP and e-PTFE membranes [54], BM and collagen membranes [23] and BM and EMD [55], failed to confer statistically significant additive benefits in the therapy of periodontal intraosseous defects. However, according to other RCTs such adjunctive positive outcomes may result from other combinations of PRP, namely together with BM [28], DFDBA [56] and hydroxyapatite [22]. These results should not necessarily be regarded as conflicting, because the selected RCTs have examined combinations of PRP with different regenerative materials and, owing to the diversity of therapeutic modalities, no antitheses exist among the RCTs. Instead, it seems reasonable to suggest that the specific selection of regenerative materials combined with PRP is possibly important. Given the limited amount of data currently available, this hypothesis has to be evaluated by additional RCTs on the use of each specific combination with PRP. Another interesting speculation, requiring thorough evaluation in the future, is that when PRP is combined with many regenerative materials (already established to be efficacious) at the same time, its adjunctive beneficial effects might be masked by the significant regenerative outcomes provided by these materials. A third, equally valid, explanation for differences among the results of selected RCTs might be that in the case of an heterogeneous sample of studies with limited sample sizes, the role of chance would be expected to divide results into those suggesting a significant added efficacy of PRP and those not supporting such an added efficacy. Thus, within the limits of the present study, it may be concluded that the combination of biograft-HT and platelet-rich plasma though effective in improving the radiologic parameters, did not significantly enhance the clinical outcome of the therapy compared to the biograft-HT alone. However, long-term clinical trials with larger sample size are needed to evaluate the regenerative potential of this combination.

Current advances in regenerative periodontics include the use of dental stem cell therapy [57-62]. Although cell transplantation using autologous cells is expected to play a central clinical role in the future and is way ahead of the PRP technique as far as technology is concerned, the process by in itself is elaborate and expensive, requiring harvesting of pulpal stem cells from freshly extracted teeth and culturing them before transplanting them onto the site. On the other hand, the PRP technique is a quick chair side option in addition to being economical and predictable in its outcome.

\section{Conclusion}

The following conclusions were drawn from the present study:

1. Both the regenerative materials (Biograft-HT and PRP) were safe to use, without causing any immunologic or antigenic reactions in any of the patients.
2. There was a significant improvement in clinical parameters and radiographic dimensions within each group during the 6 and 9 month study period. However, the differences between the groups were not significant with regard to both clinical and radiographic parameters.

3. A highly statistically significant difference in the percentage defect resolution was observed at the test sites when compared to the control sites at the end of 9 months.

\section{Limitations and recommendation of the present study}

1. Histological evaluation was not done due to ethical considerations. Hence, as the true end point of regenerative therapy further histological evaluation of outcome of treatment with this material is needed.

2. The long term effects of these treatment options need to be assessed with larger sample size and longer study period.

3. In future, third generation probes could be used to overcome the problems with reliability of measurement of clinical recordings.

\section{Competing interests}

The authors declare that they have no competing interests.

\section{Authors' contributions}

\begin{tabular}{|l|c|c|}
\hline Authors' contributions & SS & AB \\
\hline Research concept and design & $\checkmark$ & -- \\
\hline Collection and/or assembly of data & -- & $\checkmark$ \\
\hline Data analysis and interpretation & -- & $\checkmark$ \\
\hline Writing the article & $\checkmark$ & $\checkmark$ \\
\hline Critical revision of the article & $\checkmark$ & -- \\
\hline Final approval of article & $\checkmark$ & -- \\
\hline Statistical analysis & -- & -- \\
\hline
\end{tabular}

\section{Acknowledgement}

The authors wish to acknowledge the contribution of Mr. Rajesh Agarwal, IFGL Bioceramics, LTD, for providing the bone grafts for the study; and statistician Mr. Thejasvi for carrying out the statistical analysis for the study and most importantly, Indian Council of Medical Research(ICMR), for supporting and funding this research project.

\section{Publication history}

Editor: Rolf Zehbe, Berlin Institute of Technology, Berlin. EIC: Scott Argraves, Medical University of South Carolina, USA. Received: 22-Jun-2013 Revised: 19-Aug-2013

Accepted: 14-Sep-2013 Published: 03-Dec-2013

\section{References}

1. Chambrone D, Pasin IM, Conde MC, Panutti C, Carneiro S and Lima LA. Effect of enamel matrix proteins on the treatment of intrabony defects: a split-mouth randomized controlled trial study. Braz Oral Res. 2007; 21:241-6.| Aritcle I PubMed

2. Fernandes JM, Rego RO, Spolidorio LC, Marcantonio RA, Marcantonio Junior $E$ and Cirelli JA. Enamel matrix proteins associated with GTR and bioactive glass in the treatment of class III furcation in dogs. 
Braz Oral Res. 2005; 19:169-75. | Aritcle | PubMed

3. Guimaraes Mdo C, Passanezi E, Sant'ana AC and Greghi SL. Pool of bovine morphogenetic proteins and guided tissue regeneration in the treatment of intrabony periodontal defects: I- Clinical measurements. J Appl Oral Sci. 2004; 12:70-7. | Aritcle I PubMed

4. Howell TH, Fiorellini JP, Paquette DW, Offenbacher S, Giannobile WV and Lynch SE. A phase I/II clinical trial to evaluate a combination of recombinant human platelet-derived growth factor-BB and recombinant human insulin-like growth factor-I in patients with periodontal disease. J Periodontol. 1997; 68:1186-93. | Aritcle | PubMed

5. Alpiste Illueca FM, Buitrago Vera P, de Grado Cabanilles P, Fuenmayor Fernandez $\mathrm{V}$ and Gil Loscos FJ. Periodontal regeneration in clinical practice. Med Oral Patol Oral Cir Bucal. 2006; 11:E382-92. | Pdf | PubMed

6. Paderni S, Terzi S and Amendola L. Major bone defect treatment with an osteoconductive bone substitute. Chir Organi Mov. 2009; 93:8996. | Aritcle | PubMed

7. Moore DC, Chapman MW and Manske D. The evaluation of a biphasic calcium phosphate ceramic for use in grafting long-bone diaphyseal defects. J Orthop Res. 1987; 5:356-65. | Aritcle | PubMed

8. Lange TA, Zerwekh JE, Peek RD, Mooney V and Harrison BH. Granular tricalcium phosphate in large cancellous defects. Ann Clin Lab Sci. 1986; 16:467-72. | PubMed

9. Lindhe, Thorkild K and Niklaus PL. Regenerative Periodontal Therapy. $4^{\text {th }}$ edition, Blackwell Munksguard , Clinical Periodontology and Implant Dentistry. 2003, 650-704.

10. Howell TH, Fiorellini JP, Paquette DW, Offenbacher S, Giannobile WV and Lynch SE. A phase I/II clinical trial to evaluate a combination of recombinant human platelet-derived growth factor-BB and recombinant human insulin-like growth factor-l in patients with periodontal disease. J Periodontol. 1997; 68:1186-93. | Aritcle | PubMed

11. Okuda K, Kawase T, Momose M, Murata M, Saito Y, Suzuki H, Wolff LF and Yoshie H. Platelet-rich plasma contains high levels of plateletderived growth factor and transforming growth factor-beta and modulates the proliferation of periodontally related cells in vitro. $J$ Periodontol. 2003; 74:849-57. | Aritcle | PubMed

12. Lekovic V, Camargo PM, Weinlaender M, Vasilic N, Aleksic Z and Kenney EB. Effectiveness of a combination of platelet-rich plasma, bovine porous bone mineral and guided tissue regeneration in the treatment of mandibular grade II molar furcations in humans. J Clin Periodontol. 2003; 30:746-51. | Aritcle | PubMed

13. Green DM and Klink B. Platelet gel as an intraoperatively procured platelet-based alternative to fibrin glue. Plast Reconstr Surg. 1998; 101:1161-2. | Article | PubMed

14. Marx RE, Carlson ER, Eichstaedt RM, Schimmele SR, Strauss JE and Georgeff KR. Platelet-rich plasma: Growth factor enhancement for bone grafts. Oral Surg Oral Med Oral Pathol Oral Radiol Endod. 1998; 85:638-46. | Aritcle | PubMed

15. Camargo PM, Lekovic V, Weinlaender M, Vasilic N, Madzarevic M and Kenney EB. Platelet-rich plasma and bovine porous bone minera combined with guided tissue regeneration in the treatment of intrabony defects in humans. J Periodontal Res. 2002; 37:300-6. Aritcle | PubMed

16. de Obarrio JJ, Arauz-Dutari JI, Chamberlain TM and Croston A. The use of autologous growth factors in periodontal surgical therapy: platelet gel biotechnology--case reports. Int J Periodontics Restorative Dent. 2000; 20:486-97. | PubMed

17. Camargo PM, Lekovic V, Weinlaender M, Vasilic N, Madzarevic M and Kenney EB. A reentry study on the use of bovine porous bone mineral, GTR, and platelet-rich plasma in the regenerative treatment of intrabony defects in humans. Int J Periodontics Restorative Dent. 2005; 25:49-59. I PubMed

18. Reynolds MA, Aichelmann-Reidy ME, Branch-Mays GL and Gunsolley $J C$. The efficacy of bone replacement grafts in the treatment of periodontal osseous defects. A systematic review. Ann Periodontol. 2003; 8:227-65. | Aritcle | PubMed
19. Trombelli L, Heitz-Mayfield LJ, Needleman I, Moles D and Scabbia A. A systematic review of graft materials and biological agents for periodontal intraosseous defects. J Clin Periodontol. 2002; 29 Suppl 3:117-35. | Aritcle | PubMed

20. Okuda K, Tai H, Tanabe K, Suzuki H, Sato T, Kawase T, Saito Y, Wolff $\mathrm{LF}$ and Yoshiex $\mathrm{H}$. Platelet-rich plasma combined with a porous hydroxyapatite graft for the treatment of intrabony periodontal defects in humans: a comparative controlled clinical study. J Periodontol. 2005; 76:890-8. | Aritcle | PubMed

21. Marx RE, Carlson ER, Eichstaedt RM, Schimmele SR, Strauss JE and Georgeff KR. Platelet-rich plasma: Growth factor enhancement for bone grafts. Oral Surg Oral Med Oral Pathol Oral Radiol Endod. 1998; 85:638-46. | Aritcle | PubMed

22. Okuda K, Tai H, Tanabe K, Suzuki H, Sato T, Kawase T, Saito Y, Wolff LF and Yoshiex $\mathrm{H}$. Platelet-rich plasma combined with a porous hydroxyapatite graft for the treatment of intrabony periodontal defects in humans: a comparative controlled clinical study. J Periodontol. 2005; 76:890-8. | Aritcle | PubMed

23. Dori F, Huszar T, Nikolidakis D, Tihanyi D, Horvath A, Arweiler NB, Gera I and Sculean A. Effect of platelet-rich plasma on the healing of intrabony defects treated with Beta tricalcium phosphate and expanded polytetrafluoroethylene membranes. J Periodontol. 2008; 79:660-9. | Aritcle | PubMed

24. Dori F, Kovacs V, Arweiler NB, Huszar T, Gera I, Nikolidakis D and Sculean A. Effect of platelet-rich plasma on the healing of intrabony defects treated with an anorganic bovine bone mineral: a pilot study. J Periodontol. 2009; 80:1599-605. | Aritcle | PubMed

25. Pradeep AR, Pai S, Garg G, Devi P and Shetty SK. A randomized clinical trial of autologous platelet-rich plasma in the treatment of mandibular degree II furcation defects. J Clin Periodontol. 2009; 36:581-8. | Aritcle | PubMed

26. Yilmaz S, Cakar G, Kuru B, Dirikan S and Yildirim B. Platelet-rich plasma in combination with bovine derived xenograft in the treatment of deep intrabony periodontal defects: a report of 20 consecutively treated patients. Platelets. 2009; 20:432-40. | Aritcle I PubMed

27. Kaushick BT, Jayakumar ND, Padmalatha $O$ and Varghese $S$. Treatment of human periodontal infrabony defects with hydroxyapatite + beta tricalcium phosphate bone graft alone and in combination with platelet rich plasma: a randomized clinical trial. Indian J Dent Res. 2011; 22:505-10. | Aritcle | PubMed

28. Hanna R, Trejo PM and Weltman RL. Treatment of intrabony defects with bovine-derived xenograft alone and in combination with platelet-rich plasma: a randomized clinical trial. J Periodontol. 2004; 75:1668-77. | Aritcle | PubMed

29. Chandrashekar KT and Saxena C. Biograft-HT as a bone graft material in the treatment of periodontal vertical defects and its clinical and radiological evaluation: Clinical study. J Indian Soc Periodontol. 2009; 13:138-44. | Aritcle | PubMed Abstract | PubMed Full Text

30. Camargo PM, Lekovic V, Weinlaender M, Vasilic N, Madzarevic $M$ and Kenney EB. Platelet-rich plasma and bovine porous bone mineral combined with guided tissue regeneration in the treatment of intrabony defects in humans. J Periodontal Res. 2002; 37:300-6. | Aritcle | PubMed

31. Camargo PM, Lekovic V, Weinlaender M, Divnic-Resnik T, Pavlovic M and Kenney EB. A surgical reentry study on the influence of plateletrich plasma in enhancing the regenerative effects of bovine porous bone mineral and guided tissue regeneration in the treatment of intrabony defects in humans. J Periodontol. 2009; 80:915-23. | Aritcle I PubMed

32. Lekovic V, Camargo PM, Weinlaender M, Vasilic N and Kenney EB. Comparison of platelet-rich plasma, bovine porous bone mineral, and guided tissue regeneration versus platelet-rich plasma and bovine porous bone mineral in the treatment of intrabony defects: a reentry study. J Periodontol. 2002; 73:198-205. | Aritcle | PubMed

33. Nagata MJ, Melo LG, Messora MR, Bomfim SR, Fucini SE, Garcia VG, Bosco AF and Okamoto T. Effect of platelet-rich plasma on bone healing of autogenous bone grafts in critical-size defects. J Clin 
Periodontol. 2009; 36:775-83. | Aritcle | PubMed

34. Yilmaz S, Kabadayi C, Ipci SD, Cakar G and Kuru B. Treatment of intrabony periodontal defects with platelet-rich plasma versus platelet-poor plasma combined with a bovine-derived xenograft: a controlled clinical trial. J Periodontol. 2011; 82:837-44. | Aritcle | PubMed

35. Saini N, Sikri P and Gupta H. Evaluation of the relative efficacy of autologous platelet-rich plasma in combination with beta-tricalcium phosphate alloplast versus an alloplast alone in the treatment of human periodontal infrabony defects: a clinical and radiological study. Indian J Dent Res. 2011; 22:107-15. | Aritcle | PubMed

36. Carranza, Newman, Takei and Klokkevold. Advanced Diagnostic Technique. $10^{\text {th }}$ edition, Saunders(Elsevier). Clinical Periodontology. 2010, 582

37. Sukumar S, Drizhal I, Bukac J, Paulusova V and Pilathadka S. Surgical treatment of periodontal intrabony defects with calcium sulphate in combination with beta tricalcium phos phate--a 12-month retrospective clinical evaluation. Acta Medica (Hradec Kralove). 2010; 53:229-34. I Pdf I PubMed

38. Sukumar S, Drizhal I, Paulusova V and Bukac J. Surgical treatment of periodontal intrabony defects with calcium sulphate in combination with beta-tricalcium phosphate: clinical observations two years post-surgery. Acta Medica (Hradec Kralove). 2011; 54:13-20. | Pdf | PubMed

39. Fowler C, Garrett S, Crigger M and Egelberg J. Histologic probe position in treated and untreated human periodontal tissues. J Clin Periodontol. 1982; 9:373-85. | Aritcle | PubMed

40. Ouyang XY and Qiao J. Effect of platelet-rich plasma in the treatment of periodontal intrabony defects in humans. Chin Med J (Engl). 2006; 119:1511-21. | PubMed

41. Shirakata $Y$, Setoguchi T, Machigashira M, Matsuyama T, Furuichi $Y$, Hasegawa K, Yoshimoto T and Izumi Y. Comparison of injectable calcium phosphate bone cement grafting and open flap debridement in periodontal intrabony defects: a randomized clinical trial. J Periodontol. 2008; 79:25-32. | Aritcle | PubMed

42. Shirakata Y, Setoguchi T, Machigashira M, Matsuyama T, Furuichi Y, Hasegawa K, Yoshimoto T and Izumi Y. Comparison of injectable calcium phosphate bone cement grafting and open flap debridement in periodontal intrabony defects: a randomized clinical trial. J Periodontol. 2008, 79(1):25-32. | Aritcle | PubMed

43. Carranza, Newman, Takei and Klokkevold. Reconstructive Periodontal Surgery. $10^{\text {th }}$ edition, Saunders(Elsevier). Clinical Periodontology. 2010, 971.

44. Sunitha Raja V and Munirathnam Naidu E. Platelet-rich fibrin: evolution of a second-generation platelet concentrate. Indian J Dent Res. 2008; 19:42-6. | Aritcle | PubMed

45. Strayhorn CL, Garrett JS, Dunn RL, Benedict JJ and Somerman MJ. Growth factors regulate expression of osteoblast-associated genes. J Periodontol. 1999; 70:1345-54. | Aritcle | PubMed

46. Keles GC, Cetinkaya BO, Baris S, Albayrak D and Simsek SB. Comparison of platelet pellet with or without guided tissue regeneration in the treatment of class II furcation defects in dogs. Clin Oral Investig. 2009; 13:393-400. | Aritcle | PubMed

47. Papli R and Chen S. Surgical treatment of infrabony defects with autologous platelet concentrate or bioabsorbable barrier membrane: a prospective case series. J Periodontol. 2007; 78:185-93. | Aritcle | PubMed

48. Markou N, Pepelassi E, Vavouraki H, Stamatakis HC, Nikolopoulos G, Vrotsos I and Tsiklakis K. Treatment of periodontal endosseous defects with platelet-rich plasma alone or in combination with demineralized freeze-dried bone allograft: a comparative clinical trial. J Periodontol. 2009; 80:1911-9. | Aritcle | PubMed

49. Pradeep AR, Shetty SK, Garg G and Pai S. Clinical effectiveness of autologous platelet-rich plasma and Peptide-enhanced bone graft in the treatment of intrabony defects. J Periodontol. 2009; 80:62-71. | Aritcle | PubMed

50. Del Corso M, Vervelle A, Simonpieri A, Jimbo R, Inchingolo F,
Sammartino G and Dohan Ehrenfest DM. Current knowledge and perspectives for the use of platelet-rich plasma (PRP) and plateletrich fibrin (PRF) in oral and maxillofacial surgery part 1: Periodontal and dentoalveolar surgery. Curr Pharm Biotechnol. 2012; 13:1207-30. | Aritcle | PubMed

51. Demir B, Sengun D and Berberoglu A. Clinical evaluation of plateletrich plasma and bioactive glass in the treatment of intra-bony defects. J Clin Periodontol. 2007; 34:709-15. | Aritcle I PubMed

52. Harnack L, Boedeker RH, Kurtulus I, Boehm S, Gonzales J and Meyle $\mathrm{J}$. Use of platelet-rich plasma in periodontal surgery-a prospective randomized double blind clinical trial. Clin Oral Investig. 2008; 223227.

53. Dori F, Huszar T, Nikolidakis D, Arweiler NB, Gera I and Sculean A. Effect of platelet-rich plasma on the healing of intrabony defects treated with an anorganic bovine bone mineral and expanded polytetrafluoroethylene membranes. J Periodontol. 2007; 78:983-90. | Aritcle | PubMed

54. Dori F, Huszar T, Nikolidakis D, Arweiler NB, Gera I and Sculean A. Effect of platelet-rich plasma on the healing of intra-bony defects treated with a natural bone mineral and a collagen membrane. J Clin Periodontol. 2007; 34:254-61. | Aritcle | PubMed

55. Dori F, Nikolidakis D, Huszar T, Arweiler NB, Gera I and Sculean A. Effect of platelet-rich plasma on the healing of intrabony defects treated with an enamel matrix protein derivative and a natural bone mineral. J Clin Periodontol. 2008; 35:44-50. | Aritcle I PubMed

56. Piemontese $M$, Aspriello SD, Rubini C, Ferrante $L$ and Procaccini $M$. Treatment of periodontal intrabony defects with demineralized freeze-dried bone allograft in combination with platelet-rich plasma: a comparative clinical trial. J Periodontol. 2008; 79:802-10. | Aritcle PubMed

57. d'Aquino R, De Rosa A, Lanza V, Tirino V, Laino L, Graziano A, Desiderio $V$, Laino $G$ and Papaccio $G$. Human mandible bone defect repair by the grafting of dental pulp stem/progenitor cells and collagen sponge biocomplexes. Eur Cell Mater. 2009; 18:75-83. | Pdf | PubMed

58. Akizuki T, Oda S, Komaki M, Tsuchioka H, Kawakatsu N, Kikuchi A, Yamato M, Okano T and Ishikawa I. Application of periodontal ligament cell sheet for periodontal regeneration: a pilot study in beagle dogs. J Periodontal Res. 2005; 40:245-51. | Aritcle I PubMed

59. Hasegawa M, Yamato M, Kikuchi A, Okano T and Ishikawa I. Human periodontal ligament cell sheets can regenerate periodontal ligament tissue in an athymic rat model. Tissue Eng. 2005; 11:46978. | Aritcle I PubMed

60. Flores MG, Yashiro R, Washio K, Yamato M, Okano T and Ishikawa I. Periodontal ligament cell sheet promotes periodontal regeneration in athymic rats. J Clin Periodontol. 2008; 35:1066-72. | Aritcle | PubMed

61. Huang SY, Zhang DS. Periodontal ligament cell sheet engineering: A new possible strategy to promote periodontal regeneration of dental implants. Dent Hypothesis. 2010; 1: 23-30.

62. Pandit N, Malik R and Philips D. Tissue engineering: A new vista in periodontal regeneration. J Indian Soc Periodontol. 2011; 15:328-37. | Aritcle | PubMed Abstract | PubMed Full Text

\section{Citation:}

Shetty $S$ and Bose A. A clinical and radiographic evaluation of the management of periodontal osseous defects with alloplast and platelet rich plasma. J Regen Med Tissue Eng. 2013; 2:11. http://dx.doi.org/10.7243/2050-1218-2-11 